This article was downloaded by: [University of Missouri Columbia] On: 3 November 2009

Access details: Access Details: [subscription number 908725978]

Publisher Taylor \& Francis

Informa Ltd Registered in England and Wales Registered Number: 1072954 Registered office: Mortimer House, 37-41 Mortimer Street, London W1T 3JH, UK

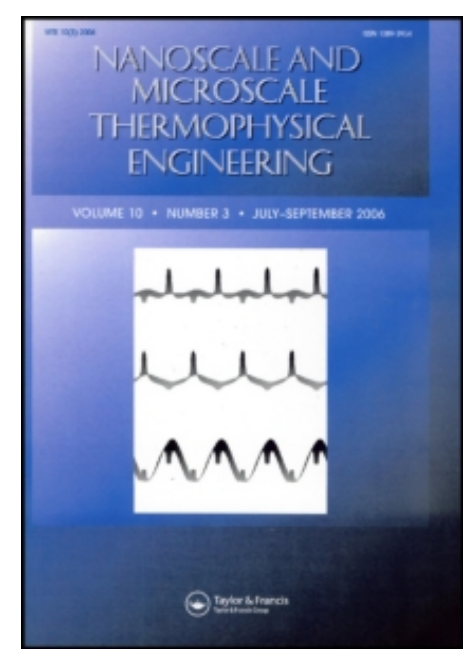

Nanoscale and Microscale Thermophysical Engineering

Publication details, including instructions for authors and subscription information:

http://www.informaworld.com/smpp/title content=t713774103

\title{
An Experimental Investigation of Thin-Film Evaporation
}

H. H. Sait a; H. B. Ma b

a Jeddah College of Technology, Jeddah, Saudi Arabia ${ }^{\mathrm{b}}$ Department of Mechanical and Aerospace

Engineering, University of Missouri-Columbia, Columbia, Missouri, USA

Online Publication Date: 01 October 2009

To cite this Article Sait, H. H. and Ma, H. B.(2009)'An Experimental Investigation of Thin-Film Evaporation',Nanoscale and Microscale Thermophysical Engineering, 13:4,218 - 227

To link to this Article: DOI: $10.1080 / 15567260903276973$

URL: http://dx.doi.org/10.1080/15567260903276973

\section{PLEASE SCROLL DOWN FOR ARTICLE}

Full terms and conditions of use: http://www.informaworld.com/terms-and-conditions-of-access.pdf

This article may be used for research, teaching and private study purposes. Any substantial or systematic reproduction, re-distribution, re-selling, loan or sub-licensing, systematic supply or distribution in any form to anyone is expressly forbidden.

The publisher does not give any warranty express or implied or make any representation that the contents will be complete or accurate or up to date. The accuracy of any instructions, formulae and drug doses should be independently verified with primary sources. The publisher shall not be liable for any loss, actions, claims, proceedings, demand or costs or damages whatsoever or howsoever caused arising directly or indirectly in connection with or arising out of the use of this material. 


\title{
AN EXPERIMENTAL INVESTIGATION OF THIN-FILM EVAPORATION
}

\author{
H.H. Sait ${ }^{1}$ and H.B. $\mathrm{Ma}^{2}$ \\ ${ }^{1}$ Jeddah College of Technology, Jeddah, Saudi Arabia \\ ${ }^{2}$ Department of Mechanical and Aerospace Engineering, University \\ of Missouri-Columbia, Columbia, Missouri, USA
}

It is well known that the thermodynamic characteristics of thin fluid films significantly differ from those for the same fluid in the bulk condition. Particularly, the pressure in film differs from the bulk value on a quantity, which depends on the film thickness. The film thickness during the evaporation process will directly determine heat transfer and fluid flow in the evaporating thin-film region. A unique experimental system was constructed to investigate the effect of heat flux on the film thickness in the evaporating thin-film region. The film thickness near the interline region was measured using one-spot thin-film analyzer F20. Temperatures at the liquid-vapor interface near the interline region were measured using the MIKRON infrared camera. Experimental results show that as the input power increases the film thickness near the interline region decreases, which is similar to the theoretical prediction.

KEY WORDS: thin film evaporation, interline region

\section{INTRODUCTION}

Since Grove et al. [1] explored the first heat pipe, many different types of heat pipes such as micro heat pipes [2], loop heat pipes [3], and nanofluid oscillating heat pipes [4] have been investigated and a number of models developed to predict the heat transfer performance occurring in those heat pipes [5-11]. As the heat flux level continuously increases, the highly efficient evaporating heat transfer occurring in the evaporator is a key to designing the high-heat-flux heat pipe. Hanlon and $\mathrm{Ma}$ [12] recently showed that the thin-film evaporation in the evaporator plays a key role in maximizing the heat transport capability in a heat pipe. Although a number of previous investigations on the evaporation and its induced fluid flow in the thin-film region confirmed that heat transfer passing through or near the evaporating thin-film region (interline region) plays an important role in the evaporating heat transfer of the evaporator, the detailed information of the effect of high heat flux on the thin-film profile and evaporation in the evaporating thin film is not known.

Manuscript accepted 20 July 2009.

This work was supported by the National Science Foundation under contract CTS-0223120.

Address correspondence to H.B. Ma, E3407 Thomas \& Nell Lafferre Hall, Department of Mechanical and Aerospace Engineering, University of Missouri-Columbia, Columbia, MO 65211. E-mail: mah@missouri.edu 


\begin{tabular}{|llll|}
\hline \multicolumn{3}{|c|}{ NOMENCLATURE } \\
$A$ & Hamakar constant, $\mathrm{J}$ & $\rho$ & density, $\mathrm{kg} / \mathrm{m}^{3}$ \\
$h_{f g}$ & latent heat of vaporization, $\mathrm{kJ} / \mathrm{kg}$ & $\sigma$ & surface tension, $\mathrm{N} / \mathrm{m}$ \\
$K$ & curvature, $\mathrm{m}^{-1}$ & Subscripts \\
$p_{d}$ & disjoining pressure, $\mathrm{N} / \mathrm{m}^{2}$ & & \\
$p$ & pressure, $\mathrm{N} / \mathrm{m}^{2}$ & & disjoining \\
$T$ & temperature, ${ }^{\circ} \mathrm{C}$ & $l$ & liquid \\
Greek Symbols & $l v$ & liquid vapor interface \\
& sat & saturation \\
$\delta$ & film thickness, $\mathrm{m}$ & $v$ & vapor \\
$\delta_{0}$ & equilibrium film thickness, $\mathrm{m}$ & $w$ & wall \\
\hline
\end{tabular}

When evaporation and fluid flow in the thin-film regions occur, liquid will flow toward the contact line due to the disjoining pressure. As a result, the dissipated energy near the contact line will be produced due to the frictional force, temperature difference, and curvature variation. Because evaporation and fluid flow in the thin-film region are directly related to the meniscus radius of curvature, thin-film profile, and interface velocity, the effect of the disjoining pressure on the thin-film evaporation and fluid flow can be found indirectly through measuring the thin-film profile and interface temperature in the thin-film region. In this way, the interfacial forces on evaporation and fluid flow in the thin-film regions can be determined. The current article presents an experimental investigation of heat flux effect on the thin-film profile and its interface temperature and, in particular, the equilibrium film thickness.

\section{EXPERIMENTAL SETUP}

An experimental system shown in Figure 1 was established to measure the film thickness and interface temperature in the thin-film region. The setup consisted of a high-power laser, one-spot thin-film analyzer (F20), infrared imaging system, a liquid supply, and a test section. The high-power laser was used to generate heat that could be directly added to the thin-film region. The high-power laser produced a maximum power of $75 \mathrm{~W}$ with a beam of 2-mm diameter, resulting in a maximum heat flux of approximately $2387 \mathrm{~W} / \mathrm{cm}^{2}$. The laser launched the laser beam directly to the substrate where the evaporation thin-film region was formed. The one-spot thin-film analyzer (F20) was used to measure the liquid film thickness with a resolution of $0.1 \mathrm{~nm}$. The film thickness measurement was directly sent to a Pentium IV computer. The infrared camera was used to measure the interface temperature of the liquid film. A liquid supply with a constant pressure head was used to provide a flow rate of liquid to the test section.

Figure 2 illustrates the test section for the formation of the thin-film region. As shown in Figure 2, two top plates and one bottom plate were used to form the liquid film with a curved liquid-vapor interface. The bottom plate with dimensions of $50.8 \times$ $76.22 \times 4.0 \mathrm{~mm}^{3}$ was horizontally placed. Each of the top plates with dimensions of $38.1 \times 50.8 \mathrm{~mm}^{2}$ were parallel to the bottom plate with a distance of $1 \mathrm{~mm}$ to form a liquid channel. As shown in Figure 2a, the gap between the two top plates was $5 \mathrm{~mm}$. Utilizing the surface tension and gap between the plates, the thin-film region with the 


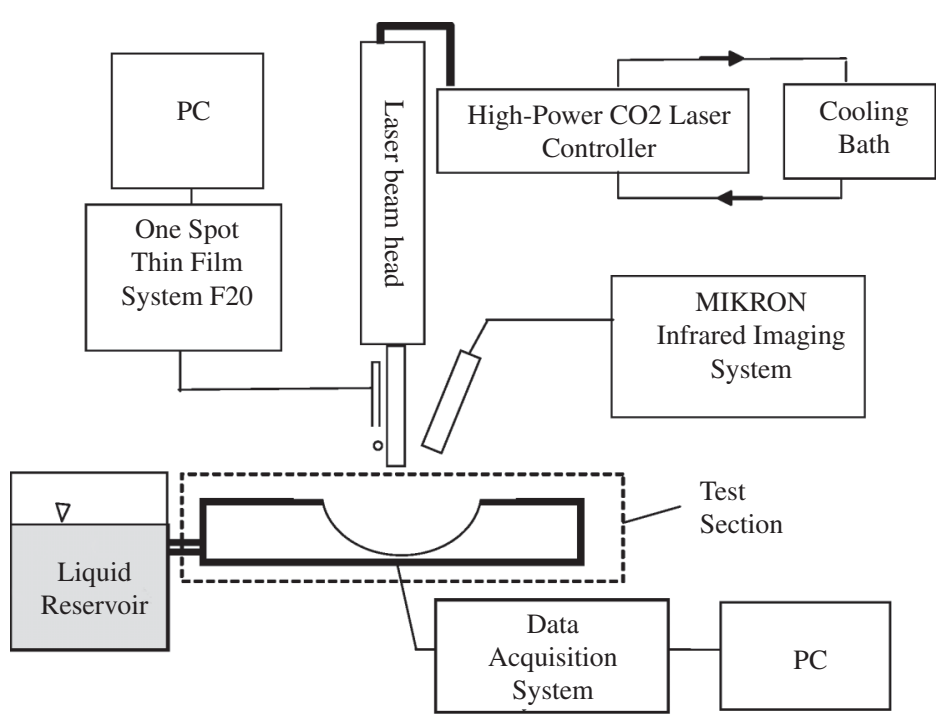

Figure 1. Schematic of the experimental setup for testing the thin-film evaporation.

meniscus radius could be formed in the center region of the open channel as shown in Figure 2.

A heat flux from a laser machine ranging from 191 to $2387 \mathrm{~W} / \mathrm{cm}^{2}$ was directly added to the thin-film region formed at the center region of the open channel. Most of the heat transferred through the evaporating thin-film region where evaporation took place. In order to measure the substrate temperature, two thermocouples were used to monitor the temperatures of the bottom plate and one thermocouple was used to measure the reservoir temperature. All thermocouples were directly connected to the data acquisition system and recorded in the computer. A noncontact temperature measurement system was used to measure the interface temperature near the interline region with a temperature resolution of $0.1^{\circ} \mathrm{C}$ and dimension resolution of $100 \mu \mathrm{m}$. The measured temperatures were saved by the IR thermal imager. The working fluid was HPLC-grade water. With the test section and facilities described above, the interface temperature and film thickness could be measured, including the heat flux level effect.

\section{TEST PROCEDURE}

Prior to the experiment, the reservoir was heated to a temperature of $90^{\circ} \mathrm{C}$. Water was then allowed to flow to the test section from the reservoir, in which the water level at the start of experiment was slightly above the test section level. Once the test section reached a steady state, the laser machine launched the beam to the center area of the open channel in the test section. The plate temperatures were automatically recorded by the data acquisition system, and the interface temperatures were monitored by the infrared imaging system and recorded manually every $5 \mathrm{~min}$. At the beginning, however, the reading from the F20 was not correct because the thickness of liquid film was too thick to be measured. Once the film thickness was less than $50 \mu \mathrm{m}$, which can be measured by the F20, the F20 started to record the film thickness. At the 


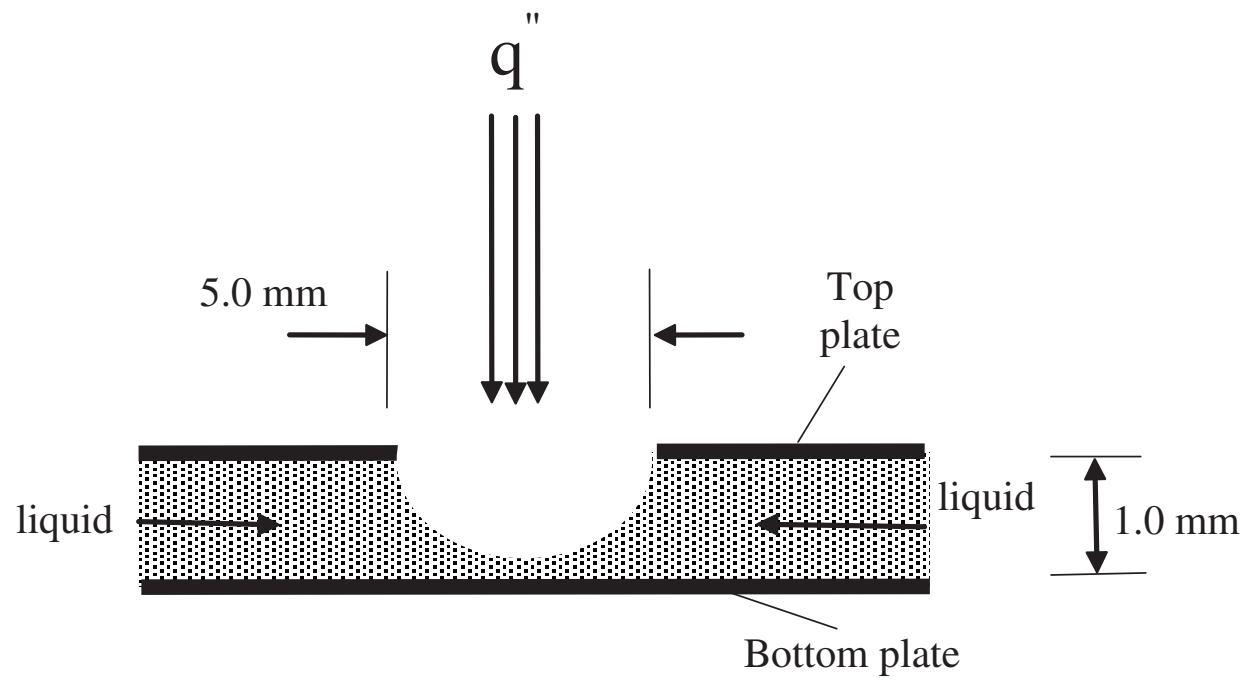

(a)

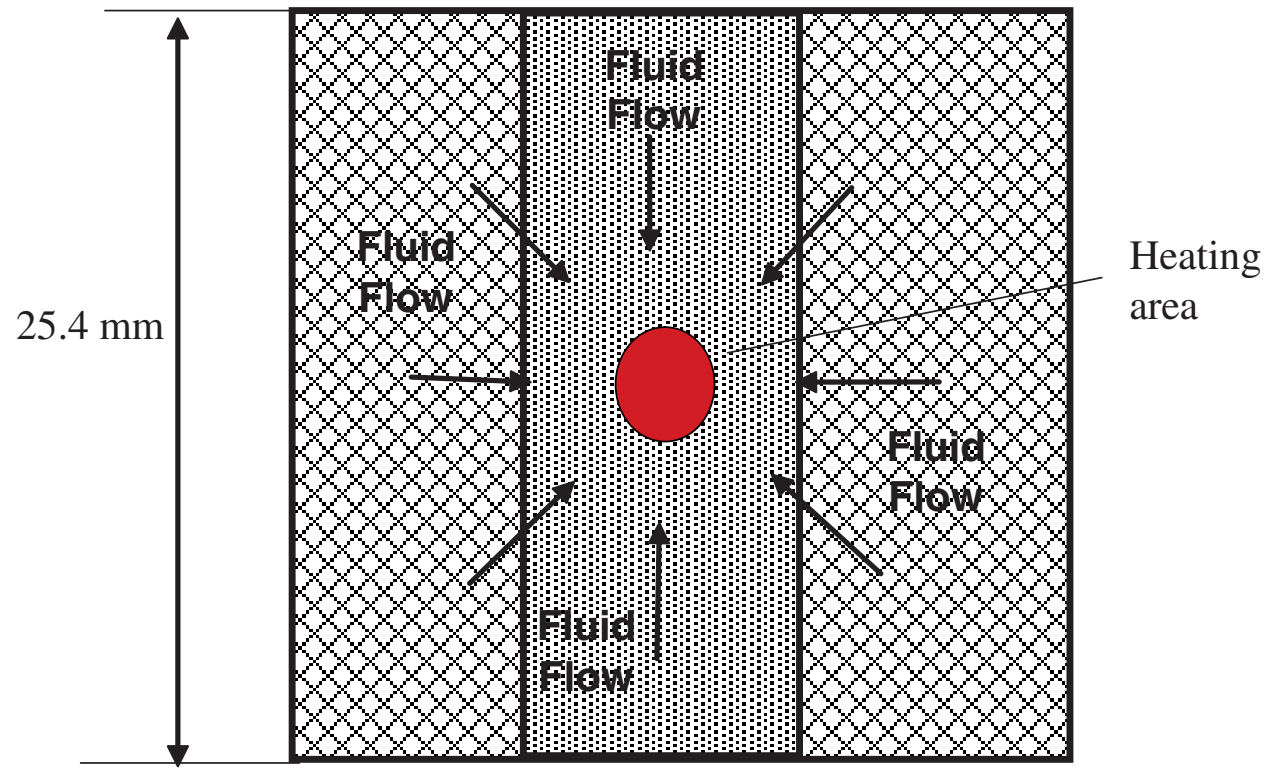

(b)

Figure 2. Test section. (a) Frontal view and (b) top view.

same time the plate and liquid film interface temperatures were recorded. Particular attention was paid to the thickness measurement just before the interface temperature suddenly rose. In this way, the film thickness variation with the thin-film evaporation and fluid flow in the thin-film region for a given condition could be determined, including the effect of heat fluxes on the nonevaporating (equilibrium) film thickness. 


\section{RESULTS AND DISCUSSION}

Using the experimental system shown in Figure 1, the extensive experimental investigation of the heat flux effect on the thin film thickness and interface temperature was conducted.

\section{Observations}

During experiments, the following observations were obtained:

1. With the test section shown in Figure 2, the thin-film region could be readily formed. When working fluid (water) was supplied to the test section, the curved shape shown in Figure 3 was formed and could be readily used to study the heat flux effect on the thin-film thickness.

2. Before heat was added on the test section, the liquid level at the center region was thick and the film thickness in the center area was about $1 \mathrm{~mm}$ as shown in Figure $3 \mathrm{a}$. As the liquid film started to be heated, the liquid film in the center region of the meniscus became increasingly thinner, as indicated in Figure 3. As the heat flux added to the heating area reached the maximum value, the liquid film at the center region reached the nonevaporating (equilibrium) film thickness, which could be measured by the F20. If the heat flux was continuously increased, the liquid film shown in Figure 3c was separated into two cornered regions as shown in Figure 3d.

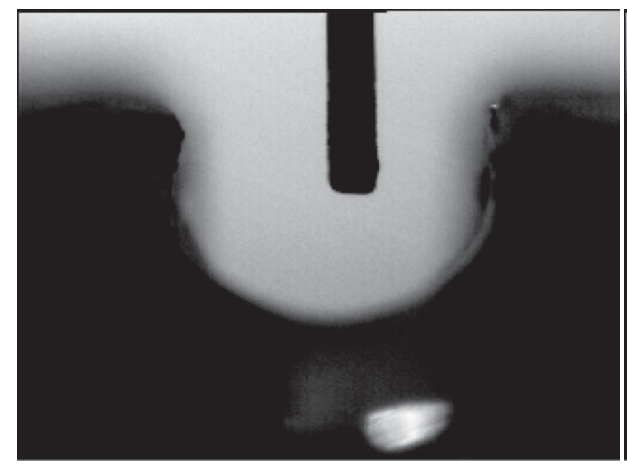

(a)

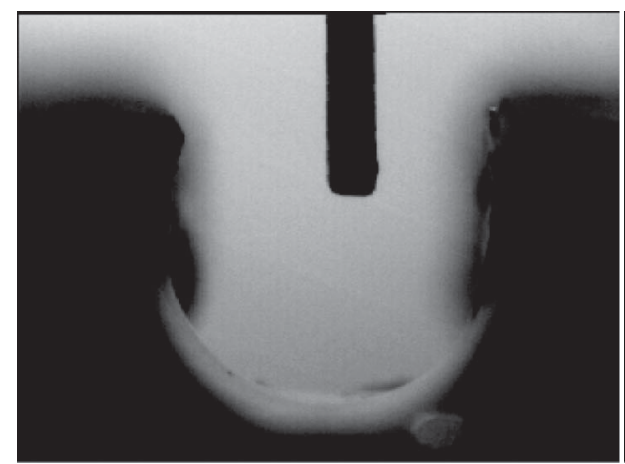

(c)

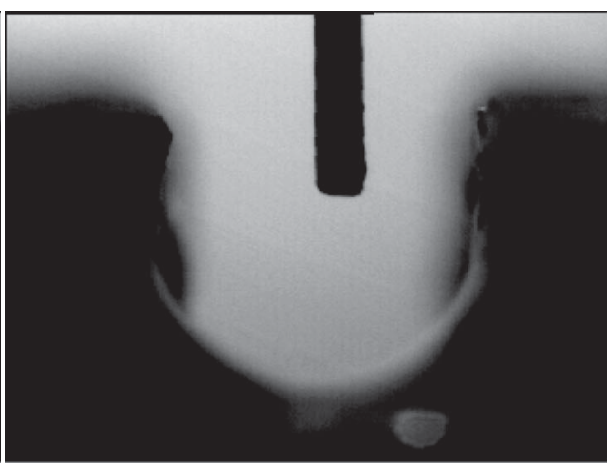

(b)

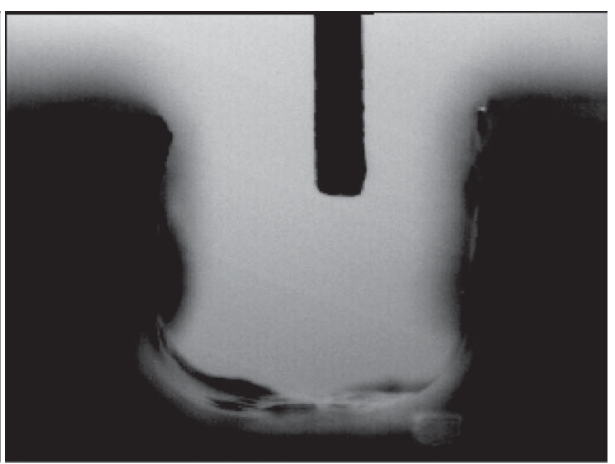

(d)

Figure 3. Heat flux effect on the thin-film profile. 


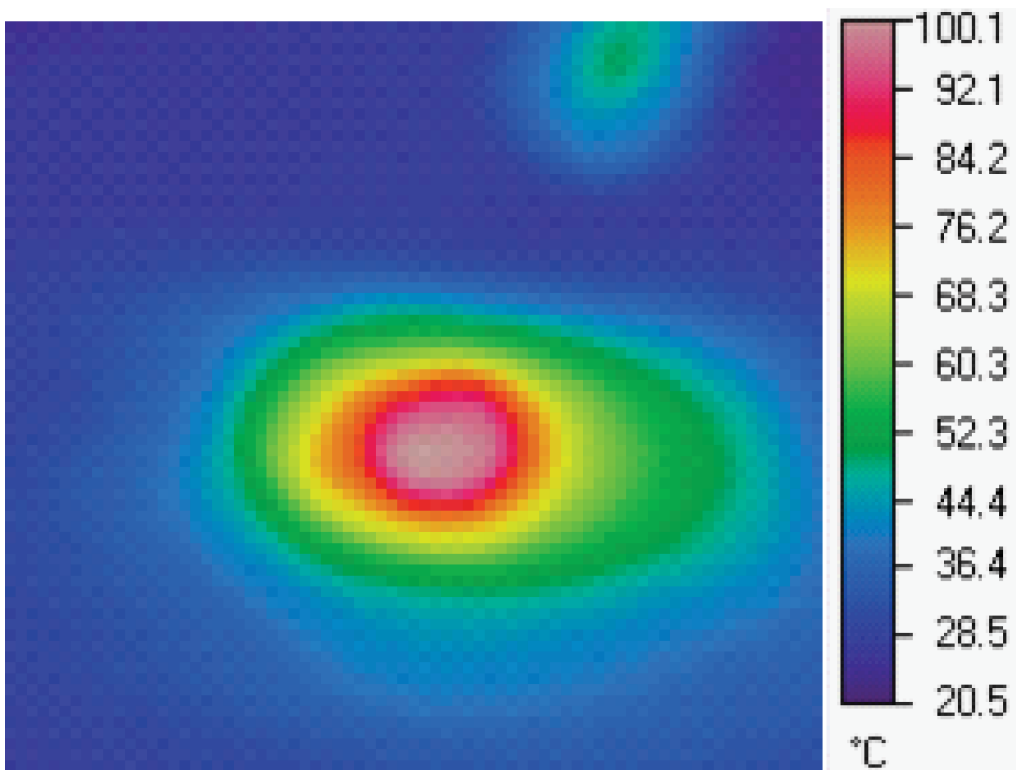

Figure 4. Heat flux effect on the temperature distributions measured by the infrared camera (power input $=6 \mathrm{~W}$ ). (Figure appears in color online.)

3. The F20 could be used to measure the liquid film thickness if it was stable and very smooth (i.e., no oscillating motions existed).

4. The infrared camera was used to measure the temperature distribution of the heated area as shown in Figure 4. With the recorded images from the infrared camera, the temperatures at the liquid-vapor interface for a given power input could be determined. When heat was added to the thin-film region, as shown in Figure 5, the interface temperature gradually increased and the interface temperature was very close to the saturation temperature of water at atmosphere. The interface temperature had been constant, equal to approximately $100^{\circ} \mathrm{C}$, for a long time and then a sudden jump in temperature occurred. Within $10 \mathrm{~s}$ the interface temperature jumped from 100 to $108^{\circ} \mathrm{C}$ and kept rising.

5. A number of experiment runs were conducted to study the heat flux level effect on the film thickness. It was found that when the input power was higher than $20.0 \mathrm{~W}$, the interface was not stable and a strong oscillating motion occurred. It was not possible to measure the film thickness and interface temperature by the F20. For the current investigation, the input power from 6.0 to $12.5 \mathrm{~W}$ was used to study the heat input effect on the film thickness variation and interface temperature.

\section{Relation between Power Input and Thin Film Thickness}

Figure 6 illustrates the effect of heat flux level on thin-film thickness. As shown, when the input power increased, the film thickness decreased. The measurements for each power input, however, were scattered in a large range. This measurement uncertainty is primarily due to the instability of liquid-vapor interface and surface roughness of the substrate. When heat was added to the thin-film region, the liquid-vapor interface was not stable, which directly affected the measurements. Using a 


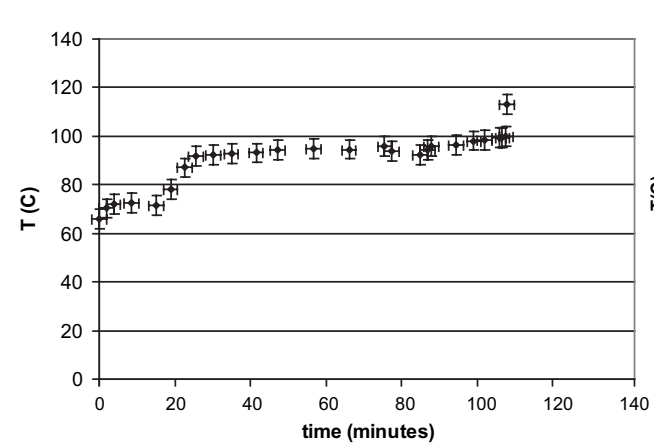

(a)

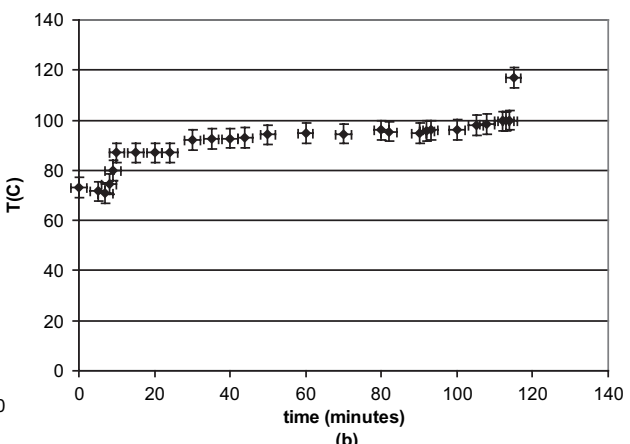

(b)

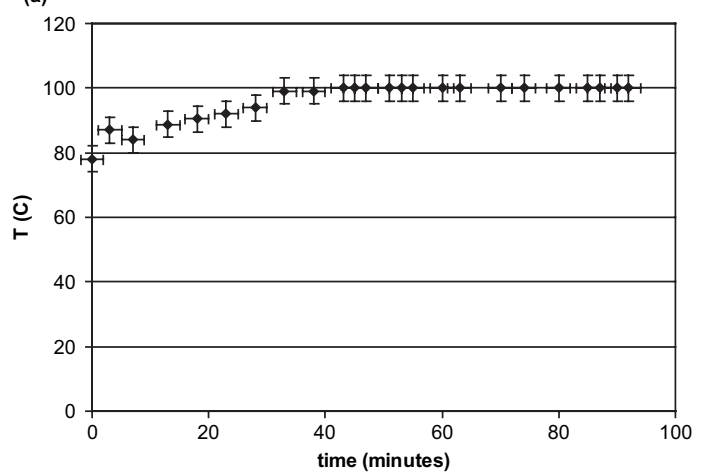

(c)

Figure 5. Liquid-vapor interface temperature variation with time at power inputs of (a) $6 \mathrm{~W}$, (b) $12.5 \mathrm{~W}$, and (c) $20 \mathrm{~W}$.

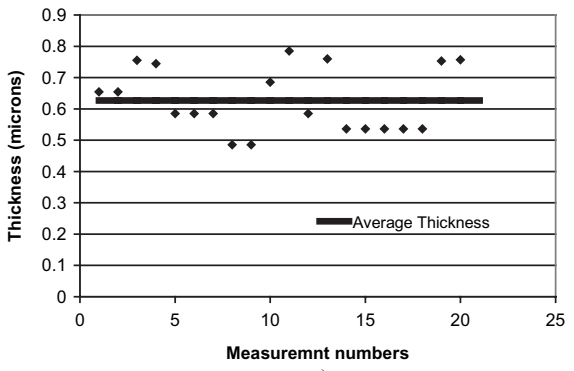

a)

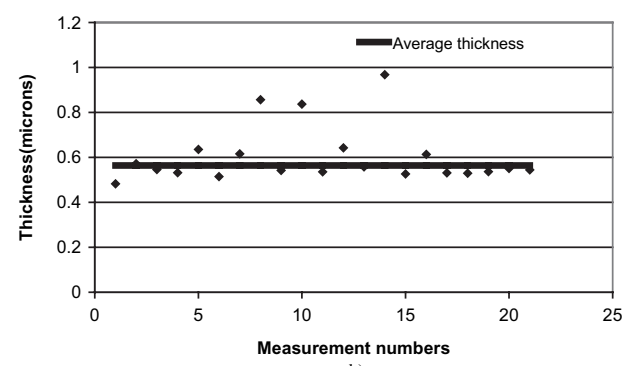

b)

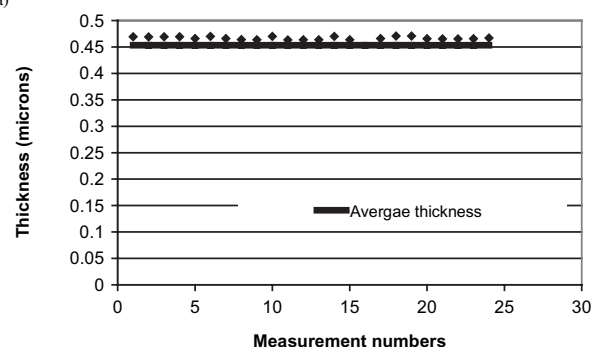

c)

Figure 6. Film thickness measurements by one-spot thickness measurement system (F20) at power inputs of (a) $5.0 \mathrm{~W}$, (b) $9.0 \mathrm{~W}$, and (c) $12.5 \mathrm{~W}$. 


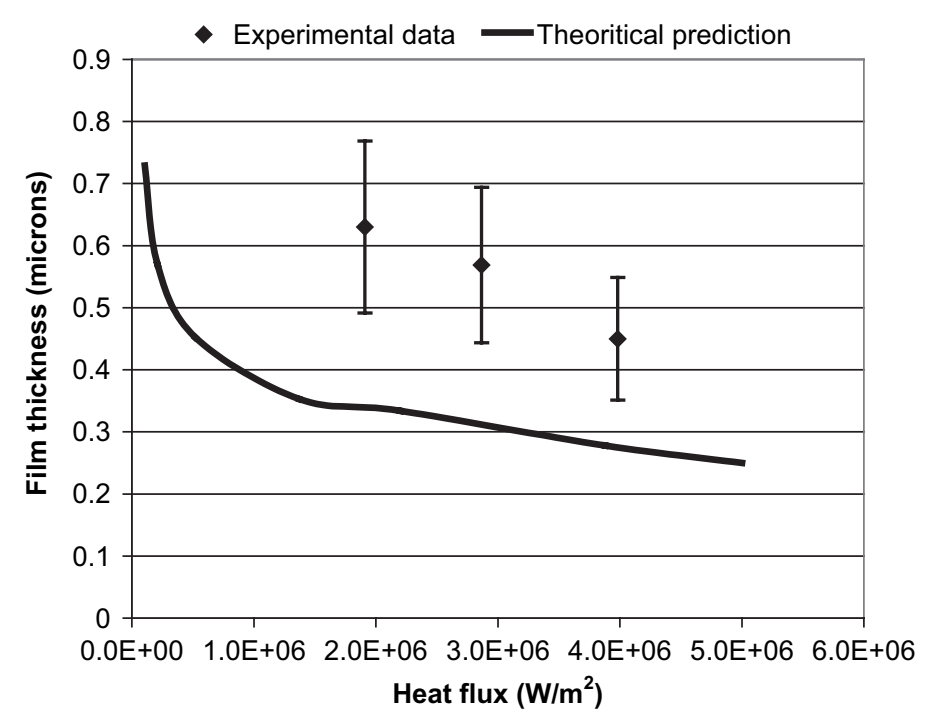

Figure 7. Comparison between experimental data with theoretical prediction.

profilometer available in the lab, the surface roughness for the substrate used in the experiment was $0.03 \mu \mathrm{m}$, which is not a perfectly smooth surface. This surface roughness would produce an additional error ranging from 6 to $16 \%$.

As shown in Figures 6 and 7, when the heat input level increased, the thin-film thickness decreased. The primary reason for this decrease is that when the heat input increases, the mass flow rate into the thin-film region increases, resulting in an increase of liquid pressure drop. In order to overcome the pressure drop, the pumping pressure in the thin-film region defined by

$$
\Delta p=\sigma K+p_{d}
$$

must increase. As shown in Figure 3, the meniscus radius was almost constant before dryout. This means that the first term on the left side in Eq. (1) has no contribution to the increase of the pumping pressure. As a result, the disjoining pressure, $p_{d}$, shown in Eq. (1) must decrease because the disjoining pressure is directly related to the film thickness. Obviously, when the heat input increases, the liquid film thickness decreases as shown in Figure 6.

A typical thin-film region consists of three regions: the equilibrium thin-film region, the evaporating thin-film region, and the meniscus thin-film region [1]. When heat is applied to the thin-film region, most of the heat will pass through the evaporating film region. If liquid evaporates in the thin-film region, the relationship between the saturated pressure and the saturated temperature can be described by the ClausiusClapeyron equation; i.e.,

$$
\left(\frac{d p}{d T}\right)_{s a t}=\frac{h_{f g}}{T_{s a t}\left[\left(1 / \rho_{v}\right)-\left(1 / \rho_{l}\right)\right.}
$$


Taking the integration from the saturated temperature to the interface temperature and because the liquid density is much larger than the vapor density, the expression for the interface temperature can be found as

$$
T_{l v}=T_{s a t}\left[1+\left(\Delta p / \rho_{v} h_{f g}\right)\right]
$$

where $\Delta p$ is the pressure difference across the liquid-vapor interface defined by Eq. (1). This pressure difference will be used to overcome the pressure drop occurring in the liquid flow. The second term in Eq. (1) is the disjoining pressure, which is the difference between the local pressure at the thin-film liquid and the bulk pressure and can be expressed as

$$
p_{d}=-A / \delta^{B}
$$

where $A$ is the Hamakar constant and $B$ is a constant that depends on the liquid type and the liquid film thickness, which is equal to 3 [13].

For the equilibrium film region, no evaporation occurs; the temperature in the liquid film is equal to the wall temperature-i.e., $T_{l v}=T_{w}$-and there is no curvature variation at the liquid-vapor interface. Substituting Eqs. (1) and (4) into Eq. (3), the film thickness in the equilibrium region can be approximated by

$$
\delta_{0}=\left[\frac{\left(1-T_{w} / T_{v}\right) \rho_{l} h_{f g}}{A}\right]^{-1 / 3}
$$

Because the film thicknesses shown in Figure 7 were measured just before the dryout, the measured film thickness should be the film thickness in the equilibrium film region. As shown in Figure 7, the film thickness in the equilibrium film region decreased as the superheat (heat flux) increased, which is similar to the experimental investigation. The difference between the experimental data and theoretical prediction is due to the assumptions of smooth surface condition, disjoining pressure calculation, and experimental errors as described above.

\section{CONCLUSIONS}

An experimental investigation on the evaporation and fluid flow occurring in the thinfilm region was conducted. A unique experimental system was established to determine the heat flux effect on the equilibrium film thickness and interface temperature. The experimental results indicate that the one-spot film thickness measurement system - i.e., F20 - can be used to measure the film thickness and demonstrated experimentally that as the heat flux increased, the film thickness in the equilibrium film region decreased. This experimental work will provide a better understanding of heat flux effect on the thin-film evaporation.

\section{REFERENCES}

1. G. Grover, T.P. Cotter, and G.F. Erikson, Structures of Very High Thermal Conductance, Journal of Applied Physics, vol. 6, pp. 1990-1991, 1964. 
2. B.R. Babin, G.P. Peterson, and D. Wu, Steady-State Modeling and Testing of a Micro Heat Pipe, ASME Journal of Heat Transfer, vol. 112, no. 3, pp. 595-601, 1990.

3. Y.F. Maydanik, S.V. Vershinin, M.A. Korukov, and J.K. Ochterbeck, Miniature Loop Heat Pipes-A Promising Means for Cooling Electronics, IEEE Transactions on Components and Packaging Technologies, vol. 28, no. 2, pp. 290-296, 2005.

4. H.B. Ma, C. Wilson, B. Borgmeyer, K. Park, Q. Yu, U.S. Choi, and M. Tirumala, Nanofluid Effect on the Heat Transport Capability in an Oscillating Heat Pipe, Applied Physics Letters, vol. 88, pp. 1161-1163, 2006.

5. T.P. Cotter, Principles and Prospects for Micro Heat Pipes, Proceeding of the 5th International Heat Pipe Conference, K. Oshima, Y. Kobayashi, M. Murakami, and K. Neqishi (eds.), May 14-18, 1984, Tskuba, Japan, pp. 328-335, Japan Technology \& Economics Center, Tskuba, Japan, 1984.

6. G.P. Peterson and H.B. Ma, Theoretical Analysis of Theoretical Maximum Heat Transport in Triangular Grooves A Study of Idealized Micro Heat Pipes, Journal of Heat Transfer, vol. 118, pp. 731-739, 1996.

7. H.B. Ma and G.P. Peterson, Experimental Investigation of the Maximum Heat Transport in Triangular Grooves, Journal of Heat Transfer, vol. 118, pp. 740-745, 1996.

8. H.B. Ma and G.P. Peterson, Temperature Variation and Heat Transfer in Triangular Grooves with an Evaporating Film, Journal of Thermophysics and Heat Transfer, vol. 11, pp. 90-97, 1997.

9. H.B. Ma and G.P. Peterson, The Minimum Meniscus Radius and Capillary Heat Transport Limit in Micro Heat Pipes, Journal of Heat Transfer, vol. 120, pp. 227-233, 1998.

10. D. Khrustalev and A. Faghri, Heat Transfer During Evaporation on Capillary Grooved Structures of Heat Pipes, Journal of Heat Transfer, vol. 117, pp. 740-747, 1996.

11. P.C. Stephan and C.A. Busse, Analysis of the Heat Transfer Coefficient of Grooved Heat Pipe Evaporator Walls, International Journal of Heat and Mass Transfer, vol. 35, pp. 383-391, 1992.

12. M.A. Hanlon and H.B. Ma, Evaporation Heat Transfer in Sintered Porous Media, Journal of Heat Transfer, vol. 125, pp. 644-653, 2003.

13. M. Potash and P.C. Wayner, Evaporation from a Two Dimensional Extended Meniscus, International Journal of Heat and Mass Transfer, vol. 15, pp. 1851-1863, 1972. 